\title{
I'm Trying to Find my Way of Staying Organized: the Socio-Technical Assemblages of Personal Health Information Management
}

\author{
Matthew Willis* \\ *Oxford Internet Institute, University of Oxford, 1 St Giles, Oxford, OX1 3JS, UK (Email: \\ Matthew.willis@oii.ox.ac.uk)
}

\begin{abstract}
Personal health information management (PHIM) is a broad endeavor that requires the patient to navigate many different types of information. Including patients performing a variety of tasks and roles to make information useful. I ask the question: what practices constitute a patient's personal health information management socio-technical assemblage? By doing this I am interested in understanding how PHIM is an assemblage of different actors, tools, technologies, information, and materialities that form a heterogeneous network to motivate the patient's health maintenance and wellbeing. I describe information practices, planning and sense making practices that patients engage to begin to define this assemblage, and the social actors and materialities that manifest and stabilize. Then, I discuss three key commitments learned from this approach, namely: the personal aspect of PHIM, the role of physical and digital materials on PHIM, and the role of information practice materialities.
\end{abstract}

Keywords: Materialities, My HealtheVet, Patient centered-care, Personal health information management, Personal health record, Qualitative research, Socio-technical assemblage

\section{Fractured practices: the disconnect between personal health records and personal health information management}

There are times throughout our lives when we become a patient. Being a patient can be an information-intensive activity that not everyone is prepared for (Hersh 2002). This can involve managing pathologies, seeking information, engaging in preventive health activities, or organizing personal health information. All these activities are cognitively intense and, most importantly, the strategies a patient can employ to manage health information are highly personalized and deeply embedded in other aspects of the patient's life. A report on personal health information management and the design of consumer health information technology for the Agency for Healthcare Research and Quality, found multiple gaps in knowledge of this area. Among them are the need to understand situated personal health information management (PHIM) practices, functional requirements of technology and design philosophies, motivations to engage in PHIM, and the further conceptualization of PHIM as a wholly different activity or special case of personal information management (Agarwal 2009).

There is an inherent cognitive challenge found in all information management activities, it is the mismatch between the complexity of people's lives and their 
cognitive ability. Agarwal (2009) points out the three specific mechanisms in this mismatch are: (1) to remember what is known, (2) find what is needed, and (3) to manage every piece of information on the personal self, for the personal self, at the level of the personal self, and by the personal self. These three components of information management cognitive challenges are further complicated by the growing number of mobile devices (Smith 2012) and the expanding notion of everyday health and quantified self-metrics (Swan 2009). This means that there is more information a patient can interact with, track, manage, read, and visualize. This increase in information availability and tools for managing health information also points to multiple configurations in which physical and digital health information can be collected, stored, and accessed. This leads to a variety of ways that health consumers engage with information in a process of sense making (Jones 2008). Patients also have technology preferences which may depend on the task they need to accomplish (Hill et al. 2012).

Lahtiranta's (2009) review of 27 personal health information management publications identified three categories of challenge. First, patients try to integrate different types of information (i.e. personal, professional, and health related) into their health information management. Second, patients often need further support to make health related decisions based off the information they have. The act of making decisions and decision support presents further challenges for the individual and the information they use. Third, sharing information with different people, including personal contacts, different professionals, and medical personnel, all create challenges based on the context and how that information is being used by each person and the role they occupy. Additionally, Lahtiranta echoes the call to problematize health information management and expand the concept into an activity that happens throughout a lifetime.

The personal health record (PHR) is a tool created to address the patient's need for information, to help manage and access data, and to share that information with others (Kim and Nahm 2012). The PHR is a remarkable and interesting technical system to analyze because of its variety of technical configurations, affordances to the design, influence on the patient-provider relationship, and impact on patient selfmanagement. There is a wide spectrum of use and implications in the over 200 PHR systems in the US (Nazi et al. 2010) that are in use or in development, yet these differences in design and approach must culminate in a single vision: to supply patients with information about their healthcare. This vision becomes clouded when factoring in the aforementioned challenges to health information management. This often means that the usable system is different than the original organizing vision of the PHR (Davidson et al. 2015; Østerlund et al. 2011). To help guide the development and standardization of PHRs, there are over 15 different standards on medical nomenclature and terminology, structure of semantics for documents and data, privacy, document templates, and technology platforms for interoperability (Roehrs et al. 2017).

PHR platforms can be classified by how they pull data from an information source. There are four arrangements of data flow for a PHR which can be tethered 
to (1) the electronic medical record, (2) the insurer, (3) a standalone health record app, or (4) a platform or ecosystem. Even these methods by which the PHR populates patient data has implications for the patient, the software vendors, healthcare providers, and administrators (Davidson et al. 2015). The organizational force behind a PHR also shapes the technology and its use. Some healthcare organizations have created their own PHR for use inside their healthcare system, such as Kaiser Permanente or the U.S. Department of Veterans Affairs. Other PHRs are in use across an entire country and funded by the government. This is the case in Denmark where the government introduced a PHR for its citizens called sunhed.dk (health.dk) (Østerlund et al. 2014). There are other companies that are in the business of developing and supporting their own PHR, such as the Epic Systems (Ball et al. 2008) software that any organization can purchase "off the shelf" and implement into their organizational setting. It is clear that the organizations shaping PHRs can be government, for profit, nonprofit, universities, hospitals, and insurance companies (Brennan et al. 2007).

Given the complexity of the technical systems, social policies, user requirements, organizational involvement, and personal information management practices that are attached and configured in different ways to each PHR, it is unsurprising that users experience difficulties and challenges in performing health information management tasks (Kim et al. 2009; Kutz and Ekbia 2011; Taha et al. 2013). Purin and Piras (2011) set a call for researchers to think of PHRs and similar information communication technologies as socio-technical arrangements, and that these larger environments must be considered when attempting to investigate patients and PHRs. The authors also stress the importance of PHIM, self-management of treatment regimes, and self-care as insights into patient experience, which can be extrapolated into useful design techniques and strategies. The core concept here is that PHRs do not create a seamless web for patients', caretakers', and family members' PHIM work practices. In reality, this web is maintained and constructed by the addition of heterogeneous networks of everyday objects, technologies outside of the PHR ecosystem, repeated information management practices, and the patient's interpersonal social networks (Berg 1999; Berg et al. 1998; Palen and Ballegaard 2006; Piras and Zanutto 2010).

Previous studies that further conceptualize health information management have found that acceptance by healthcare professionals and the availability of certain functionality are important for use of personal health records (Nazi 2013), the clinical and hospital environment presents unique challenges to patients use of information (Unruh et al. 2010), patients have different information needs when they are away from their home (Klasnja et al. 2010a), organizing information presents fundamental challenges to the ability to manage information (Unruh and Pratt 2008), physical objects are important to the management of information (Mickelson et al. 2015; Palen and Ballegaard 2006), caretakers support the work of the patient (Nunes and Fitzpatrick 2015), that health information management permeates everyday life and record keeping requires 
articulation work (Piras and Zanutto 2010). Each of these studies are important to understand cumbersome patient information interaction work.

What is needed is additional understanding and conceptualizing of personal health information management. Not as a process, particular routine, or a list of practices that occur. But as an interaction between information, social actors, situated practices, knowledge of the patient's own health, organizational techniques, and technologies that mediate information. Piras (2016) provides an essential step toward theorizing PHIM by deconstructing the often-conflated terms of observations of daily living, patient-generated health data, and personal health information management. Not only does he show that these terms underpin entirely different notions of health data, models of the patient-provider relationship, and the basic concept of what health is, but also shows that of all the terms used PHIM is the most unstructured and broad in set of practices and implications (Piras 2016). These prior findings show that what is needed is a way to bound what PHIM is and what disparate elements are connected to construct a larger structure.

It is to this end I explore the potential of a personal health information management assemblage to make sense of the shifting information materialities, diverse practices, patient experiences and knowledge, various social actors, collection of information communication technologies, and learned techniques for being a patient and performing work that is information intensive. Specifically, I focus on the work of patients to understand how these health information assemblages stabilize and how specific needs, such as PTSD and mental health patients, form a meaningfully different structure than surgery or long-term disease patients. This approach coalesces previous findings and insights from PHIM and PHR research while contributing new analytical insight into patient work and advancing future visions of patient-centered models of care.

The work featured to this point show how complex and multi-faceted it is to engage with personal health information management and personal health records. Most important is the personal aspect, constantly highlighted by both the title of PHIM and prior research consistently iterate the personal nature of this enterprise. I posit that the application of assemblages from a practice perspective will help to understand what PHIM is in a systematic way and will synthesize much of the disparate findings into a clear framework. The following section offers the perspective of assemblages augmented by a practice perspective to clarify what PHIM is beyond information management.

\section{Bringing it all together: assemblages and practice theory}

A patient is handed a letter their spouse received in the mail about an upcoming appointment at the hospital. The patient, upon seeing the letter, remembers to log into their health record and print out a sheet of lab work from the last clinical visit. They pair the lab work printout with a list of questions written on a piece of paper for the doctor. Ask their spouse a few questions about the letter and the upcoming 
appointment. Then, they take this paper and printed document and secure them together in between the pages of a book they bring to the hospital to read when they have downtime. They set these items aside in their home on a specific and meaningful location in preparation for an appointment the next day. They are driven to the appointment by their spouse, who will also attend the appointment with the patient.

This is small in scope but common example of patients working with health information. This example shows a few different components: the printing out of information from an online personal health record, generating a list of questions beforehand on a piece of paper, information occurring through conversation with the patient's spouse, the preference of reading a book in the waiting room, the importance of space and place, the consideration and purposeful use of materials to represent the information, having a family member present in the appointment, and how to organize and transport everything. Each of these components come together in a type of harmony that allows for the patient to be well prepared and ready for their clinical appointment.

In this example are a series of decisions, information systems, information mediated by technology, knowledge and expertise in the patients' health and personal relationships that all allow the management and use of health information to occur. Assemblages are a way of organizing different entities for a certain time to allow a particular outcome or goal to occur. I argue that two distinct catalysts occur for assemblages to be made possible, and when these catalysts are present, or put into action, they constitute a more holistic and encompassing perspective of the patients personal health information management. The first catalyst are information practices, planning, organizing, sense making, and different information resources are put into play. However, those practices and resources do not wholly constitute PHIM alone. The second catalyst are the physical and digital materialities (Jarrahi 2015) of the tools and information representations, as well as the personal network of family members, carers, friends, and healthcare providers that are connected to this assemblage. These catalysts in concert form an assemblage of information practices, tools, technologies, information resources, and people that places the patient in the center of this assemblage. Both of these broad categories I describe catalyze the entire assemblage, making it an endeavor that is purposeful and personal. Patients are agentic throughout this process, doing purposeful work to bring together different elements that give way to a heterogeneous network that is personal health information management. This is why I use the term catalyst to describe assemblages of PHIM. Because the term connotates the act of change, transformation, and something that causes activity between different entities.

This perspective on PHIM requires some brief background as to what assemblages are, and how the concept relates to the phenomenon in question. The term assemblage originates from the French term agencement. Although some sense of the word is lost in translation it essentially means a collection of heterogeneous parts linked together to form a functional whole, it should be noted that agency is of particular importance to this concept. The term was first used by French philosophers 
Gilles Deleuze and Félix Guattari and is elaborated on in their book A Thousand Plateaus (Deleuze and Guattari 1987). They note there is no single organizing principle or hierarchy to what an assemblage is or how it functions it is not a theory but an analytical tool. Attempts to construct an assemblage theory have been the work of Manuel DeLanda to help detail social complexity and argues that assemblages have very few boundaries or constraints (DeLanda 2006). Some of this work has been used by scholars in infrastructure studies to understand the potential for unplanned growth in information infrastructures (Henningsson and Hanseth 2011). A similar actor network theory inspired approach to assemblages has been the work of Foucault, Latour, Callon and others. However, the work in this article is closer to how Sassen uses the phrase, drawn from Foucault, to analyze mesoscale arrangements and institutional connections of information flows in global finance and how technologies are used to support and model these arrangements (Sassen 2005). Although the work presented here is not in the domain of global finance, I take a smaller scale approach and use the concept of assemblage to understand personal and contextually bound arrangements using an interpersonal and practice-oriented approach (Sawyer et al. 2014). This is to say that I conceptualize the use of assemblages as configurations or patterns of tools and practices that shape work and make certain types of information management work possible.

Assemblages have five features that seem to be universal to their understanding (Muller 2015). First, assemblages are relational. This is the essential dynamic of Deleuze's work that multiple different entities (human or non-human parts) are linked together by a particular set of relations or relations directly related to people and objects. Second, the assemblage is productive. This can be producing new meaning, new views, new organizations or new possibilities. In the cause of the work presented here and assemblage thinking in similar areas, it is the production of new possibilities to work or to make a certain type of work possible. Assemblages are not representations or descriptions of the world but more action oriented. Third, there are no rules on what can be related, humans do not have to be linked together but ideas and practices can be connected. Fourth, assemblages are in a constant state of stabilization and destabilization, or as Deleuze and Guattari refer to as deterritorialization and reterritorialization. Assemblages do not exist permanently but are a function of certain factors that create or stabilize the assemblage. Fifth, assemblages bring together fragmented parts through a form of desire or harmony. It is this desire that attracts what are otherwise disparate objects that become connected through an idea, practice, or other relationship.

The assemblage perspective is a materialist position that helps to frame and make sense of all the complex information, social, and material practices and actions that patients initiate and engage. However, assemblages are not a complete wholesale theory and for the purposes of this study, they need to be augmented with an additional concept to provide analytical clarity and ground the study in a theoretical perspective. Specifically, a practice based approach is employed to understand the broader context of how patients create and build 
these assemblages through routines and practices. Although there are various theories and perspectives of social practice, they are all a turn against structurally deterministic readings of human action and interaction (Wulf et al. 2015). A practice approach is important here because practices offer a deep understanding of the world as complex and made up of interdependent entities, and that meaning and understanding arise from the relations to and between these entities (Gherardi 2012). Particularly when information is concerned because all practices involve information, but practices can also emerge around the use of information itself (Cox 2012). These notions of practice overlap closely with that of assemblages in that practice is how information is generated and shared. The use of practice in this study is a sensitizing concept to focus on the activities and routines of how veterans, their caretakers, and the practice team all repeatedly use and interact with tools, technologies, artefacts, and other actors when engaging in health information management. Particularly, by looking at the observations of health information management as it is unfolds in real life, and that these practices are situated in a specific context and time in the person's life (Kuutti and Bannon 2014).

I want to suggest that attending to PHIM as a practice-oriented assemblage provides a holistic framework to better understand the phenomenon of PHIM, the actions and needs of the patient, and that this approach has important implications for patient-centered models of care. I also posit that this perspective moves scholarship in the direction that Purin and Piras (2011) set a call for, which is that PHRs and similar technologies are socio-technical arrangements of different systems and user context. I concur with their call to action and motivate this research by bringing together studies of PHR use with patients that engage in personal health information management. I want to emphasize that the need for an assemblage perspective on personal health information management arises because people have to do work to manage, organize, and understand information with the end goal of maintaining, improving, or otherwise being mindful of their health. This work is one of the reasons that the PHR tool was developed. However, this work is complex and strewn across different technologies, file formats, people, locations, psychological moods, and current health status of the patient's body. If a patient typically writes down questions they have for the doctor but cannot focus on doing this task because of the pain and discomfort they feel and have a low attention span, detailing the patient's practices without accounting for additional critical contextual information loses key components of the patient's contextual work. These elements cannot be meaningfully separated but must be considered part of the entire system (Orlikowski and Scott 2008).

To assist in the task of showing the relationship between an assemblage perspective and the phenomenon of personal health information management as an assemblage, I map these together in Table 1 below. The assemblage features are the five features as previously summarized by Muller (2015) and drawn primarily from the works of Deleuze and Guattari (1987), DeLanda (2006), and Bennett (2010). 
Table 1. Links between assemblage features and personal health information management.

\begin{tabular}{ll}
\hline Assemblage Features & Personal Health Information Management \\
\hline $\begin{array}{l}\text { Relational arrangements of } \\
\text { different entities }\end{array}$ & $\begin{array}{l}\text { Relationship between patients and their personal practices, } \\
\text { information practices, the patient's body and previous } \\
\text { experiences brought together by the context of the patients } \\
\text { health and wellbeing. }\end{array}$ \\
Pllow for and support patient self-management, asking \\
questions of healthcare providers, participating in and being \\
informed about care, discovering new ways to cope with \\
disease and illness, and produce new practices.
\end{tabular}

The review of PHR and PHIM literature reveal a gap in the conceptualization of PHIM work and a dearth in understanding of the PHR as an information management tool and the connection to the rest of the work that patients perform. Then, I discuss the assemblage in conjunction with a practice theory perspective as a way to advance our understanding of personal health information management. To this end, I pose the following research question: What practices constitute a patient's personal health information management socio-technical assemblage?

\section{Research design, setting, data collection, analysis}

This site of this study is a medical facility of The United States Department of Veterans Affairs (VA). The VA provides a rich setting to observe emergent phenomena of patient information management in conjunction with personal health record use because the VA is the world's leader in using telehealth and has one of the largest telehealth programs in the world (Lindeman 2010). The VA also offers a personal health record system that has one of the largest adoption rates for a PHR, making it feasible to understand the role of the PHR in information management activities. This is an important factor to seek out in research, especially when PHR adoption rates are typically low (Archer et al. 2011), making users of PHR difficult to include in research.

Prior work in PHRs and PHIM has shown the importance of qualitative methods to gain an in-depth understanding of the previously reviewed complex work practices, interactions, and relationships. (Civan et al. 2009; Greenhalgh and 
Swinglehurst 2011; Klasnja et al. 2010a; Palen and Ballegaard 2006; Piras and Zanutto 2010; Pratt et al. 2004; Unruh and Pratt 2007; Ventres et al. 2006). I employ a case study approach in this research to best understand each patient and their individual PHIM practices. As per Yin's (2014) directions on case study design, each case was holistic in the context of personal health information management. Cases were selected for variation in demographics and availability of caretakers. This selection criteria resulted in about half of the cases having no caretakers and the other half having at least one other caretaker. Cases were compared to look for emergent concepts around how health information tools and practices are arranged. By selecting different participants from a shared context or similar setting, mutual agreements and understandings between and among participants were uncovered, this is known as intersubjectivity and helps to triangulate data sources and generalize concepts (Walsham 2006; Yin 2014).

To inform recruitment for this study I submitted a data request, a standard internal form used by VA researchers to aid in recruitment for research projects, to the VA medical facility where fieldwork was performed. The data request form asks for sets of "filters" that a data analyst then applies to the master list of veterans. For the purposes of recruitment for this research, the filters used restricted the recruitment list by geographic location and for My HealtheVet account activation. This data request and associated study was reviewed by both a university research ethics committee and the VA internal review board. The data request resulted in a recruitment spreadsheet that provided names, contact information, demographic information, period of service, confirmation of My HealtheVet account activation, count of visits to their provider in the last year, and the names of each veteran's primary care provider that were all located near or around the VA medical facility where this research took place. Using this recruitment list, I selected participants who met the study recruitment criteria. Including: use of a My HealtheVet account, different levels of use of the PHR (Agarwal 2009), Internet access at home to use the PHR, patients with different arrangements of caretakers (one caretaker, two caretakers, no caretakers, living alone, living with others), different configurations of mobile technology (laptops, tablets, smart phones), representation across different age groups, experience either managing their own health information or someone else's, use of objects beyond the PHR for information management (Piras and Zanutto 2010) and, of course, participants that are comfortable talking about health events they have experienced. During a first contact phone call, participants asked questions about the study and were told the expectations for participation in the study.

Interviews occurred immediately before or after a patient's clinical appointment so that patients and their caretakers were able to share important documents they had on their person related to the appointment. Additionally, experiences most relevant to this research would be fresh in the participant's memories. All interviews with patients were conducted using a semi structured interview protocol to allow for consistent data gathering. Probing questions and follow up questions were used as the interview unfolded to investigate the concepts relevant to this study. The nature of 
all patient interviews was to understand the use of information, strategies developed, and organizational techniques of the patient. This includes which technologies are used, what the patient does, what other family members and caretakers do, decision criteria and logic behind choices for why to use paper or a digital technology, and how they use My HealtheVet for health information management to name a few subjects raised in each interview.

Additionally, patients with a mobile phone allowed me to observe the ways in which they used the phone for health information management. I also performed over $20 \mathrm{~h}$ of observation of patients in waiting rooms, pharmacy pickup areas, common areas, and throughout the medical center. This observation enriched the overall understanding of the role of documents and information provided to the patient in the medical center. It also provided additional data about the type of information work patients perform in the waiting room and I observed the different material documents patients keep on their person. I also observed the providers' work in their offices out of clinical hours. Each provider was asked about their workflow and interaction with the rest of the care team, the patient and the technologies they use and how they are configured. As in the discussions with each patient, I asked providers about events and specific scenarios to ground their arrangements of tools and technologies in practices.

The qualitative coding framework that provided substantive analysis is a twocycle method. The first cycle used process coding and the second cycle pattern coding (Saldana 2013). Throughout the cycles of data coding, I wrote analytic memos during all coding cycles as both a reflective practice for data analysis and to serve as an additional analytical tool. Also, throughout memo writing and data coding, I developed visual maps as an additional analytical tool. I plotted the patient on the map and drew nodes and edges connecting the different actors while the interview was fresh in memory. I revised this map with each coding cycle, viewing it alongside the textual data. This practice served as an additional check on the data and allowed me to add any missed connections, technologies, practices, or actors. Also, the map allowed me to visualize the interview data as I progressed through coding. This practice resulted in a highly-organized interview transcript, set of memos, and detailed visual map. Surveying the final products of this analytical process left me with the notion that they clearly and accurately represented each case in great detail (Miles and Huberman 1994; Northcutt and McCoy 2004).

\section{Findings: assembling personal health information management practices}

All 22 patients participating in this study are U.S military veterans enrolled in My HealtheVet (MHV), the official health record of the Department of Veterans Affairs, who maintained an in-person authenticated account. In-person authentication means that the veteran has authenticated their identity in person at a VA My HealtheVet coordinator's office at their local VA Medical Center using a form of government ID. This level of authentication grants the veteran access to the entirety of their medical 
record, including ability to access the medical education library, renew prescriptions, send secure messages to their various health providers (specialist and primary care), view lab work and test results, see clinical notes including mental and behavioral health clinical notes, view an appointment calendar, and finally export all documents into a variety of document formats. Having this functionality available to the patient was obviously essential to understanding health information management in patients that have access to a PHR.

The personal health information management assemblages constructed by participants in this study were all heterogeneous collections of tools, technologies, practices, various social actors, and different configurations of all these items. While there were many broad similarities between each of the patient's assemblages, they were personal in nature and contained specific adjustments given the situated characteristics of each patient. In general, there are two distinct catalysts that occur throughout the process of patients PHIM practices that constitute their personal assemblage. First, what I call priming the assemblage, consisting of mostly the interaction of information practices. This is the sense making work, planning, consideration, and other information practices that patients perform to create relational purpose in the assemblage, to establish the purposeful agentic relationships of what Deleuze calls the form of desire or harmony. The second catalyst, consisting mostly of actor and material conceptual components, is the actual maintenance and stabalization of the assemblage. Specifically, where the assemblage is stabilized to a point where the social actors and materials are put into action. I call this the actuation of the assemblage. Where planning and sense making become actions that can bring together personal networks in consideration of the existing materialities. These two catalysts are not to be taken as a linear process or two phases that have an explicit beginning and ending with a predefined direction. Instead, these are iterative and cyclical themes that occur many times over to construct the patient's personal health information management assemblage. Table 2 below provides a summary of the constitution of personal health information management assemblages. The sections beyond Table 2 unpack these practices and characteristics, following the order established in the table.

\subsection{Priming the assemblage through information practices}

The practices that emerged from my analysis concern the planning of using information, the ability to access information in how it is stored and organized, and the sense making practices of information. The immediate availability, how easily a patient can locate information, is an important practice that in part constitutes a personal health information management assemblage. Overall time to access the information is not the only factor; precise location and methodology or process to obtain the information are also relevant. This practice was also influenced a great deal by the patient's overall health condition: mental and acute health concerns mandate that health information be accessible depending on a specific health situation or 
Table 2. Summary of practices and characteristics of personal health information management that constitute the forming and continuation of an assemblage.

\begin{tabular}{|c|c|c|c|}
\hline & $\begin{array}{l}\text { Practices \& } \\
\text { characteristics }\end{array}$ & Description & Examples \\
\hline \multirow[t]{3}{*}{ Priming } & $\begin{array}{l}\text { Information } \\
\text { Practices }\end{array}$ & $\begin{array}{l}\text { These practices concern } \\
\text { the availability and } \\
\text { accessibility of information. }\end{array}$ & $\begin{array}{l}\text { - Access MHV from phone } \\
\text { - Pinning websites to home } \\
\text { screen/bookmarking } \\
\text { - Saving documents to email } \\
\text { - Creating emergency folders and } \\
\text { placing in the house } \\
\text { - Considering the need and advantages } \\
\text { of digital or physical information } \\
\text { for the task }\end{array}$ \\
\hline & Planning & $\begin{array}{l}\text { These practices concern } \\
\text { personal organising } \\
\text { of information and how } \\
\text { patients learn to use } \\
\text { information from one } \\
\text { context (hobbies) and } \\
\text { applying those practices } \\
\text { to PHIM. }\end{array}$ & $\begin{array}{l}\text { - Organizing in email using folders } \\
\text { or tags } \\
\text { - Using bookmarks or folder hierarchy } \\
\text { of pdf files } \\
\text { - Creating a filing system organized } \\
\text { by a specific topic or scheme } \\
\text { - Storing certain documents in } \\
\text { email and others on a hard drive }\end{array}$ \\
\hline & Sense making & $\begin{array}{l}\text { Using, interacting, and } \\
\text { making decisions with } \\
\text { information as a result of } \\
\text { other information practices. }\end{array}$ & $\begin{array}{l}\text { - Searching techniques } \\
\text { - Making sense of information } \\
\text { through organizing and } \\
\text { management practices } \\
\text { - Current physical and mental state } \\
\text { - Answering questions through } \\
\text { interacting with information }\end{array}$ \\
\hline \multirow[t]{2}{*}{ Actuating } & $\begin{array}{l}\text { Personal social } \\
\text { networks }\end{array}$ & $\begin{array}{l}\text { Other social actors such } \\
\text { as friends, family members, } \\
\text { and care takers work to } \\
\text { stabilize and support the } \\
\text { patients PHIM goals. }\end{array}$ & $\begin{array}{l}\text { - Provide support with } \\
\text { health specific conditions } \\
\text { - Assume and support } \\
\text { patients established practices } \\
\text { - Collaborate on information tasks } \\
\text { - Share and mediate materialities }\end{array}$ \\
\hline & $\begin{array}{l}\text { Material } \\
\text { practices }\end{array}$ & $\begin{array}{l}\text { All practices are mediated } \\
\text { by and through both } \\
\text { physical and digital } \\
\text { materials. Also, information } \\
\text { practices create different } \\
\text { materials based on the } \\
\text { personal nature of the work. }\end{array}$ & $\begin{array}{l}\text { - Physical and digital } \\
\text { ways of organizing and } \\
\text { making sense of information } \\
\text { - Purposeful decisions on what } \\
\text { materials to use for supporting } \\
\text { information management work. } \\
\text { - The same PHR and } \\
\text { identical tools have different } \\
\text { material function for different } \\
\text { patients' practices. }\end{array}$ \\
\hline
\end{tabular}

impairment. This practice manifests through actions such as pinning the Veterans Crisis website to the patients' mobile phones home screen where it can be quickly accessed at a moment's notice. The participant who did this would access those 
resources to practice the therapeutic techniques listed on the website as a guide. Another example of requiring close proximity to information is having the mental health support hotline phone numbers on speed dial or pinning other websites that contain information. Another event that occurred during the interviews and observations involved the use of the PHR and access during an emergency.

'I was referred to the emergency room a few weeks ago by my primary care [provider] and he didn't give me a lot of information, they just told me to go and the VA was closed so I had to go to a civilian emergency room and answer some questions, and I logged into My HealtheVet on my phone and showed them the prescription that I have that they wanted me to get' (Patient \#9243).

This example is of an emergency in which the patient needed to quickly provide medication information without recall of the details. However, the patient accessed that information via the PHR on the phone. Because of the patient's organization strategy and personalized information resources they were able to provide information that otherwise would have been inaccessible. Not having the ability to provide this information could be dangerous in certain circumstances, especially when medications are involved.

The practice of the accessibility and availability of information also plays out with information that has a physical materiality. Physical information, such as questions hand written on pieced of paper or a bound notebook, or websites printed on paper, can be moved closer to or further away from the person that needs it. Cases from fieldwork include storing pieces of paper in one participant's wallet, between the pages of a book to read in the waiting room and bundling paper documents together in a folder and keeping it in a secure and secret location in the house. Space and location are not only an organizational concept or way to manage and organize information (e.g. Piras and Zanutto 2010), but a concept of criticality of information, of the need of the information, and the importance of the information in a context directly connected to the patients current health status.

Another example that emerged in multiple interviews: of the participants that store their health information in a digital format, they would use email as a strategy to save specific information that they needed to keep close access to because email was ubiquitous. All the VA medical centers and community centers that participants attend provide the ability to access email through a public computer, and most all participants had phones that also provide access to their email account. Saving health information to an email folder allowed these participants quick access to documents because their email could be recalled with a single tap. Digital information that was considered further away in a patient's organizational practice is when patients archive the information on backup hard drives, requiring one - and in some cases two - passwords along with knowing a process to restore the needed information onto the desktop computer. 
Information accessibility and making sure the information is available is important not just for the patient, but for caretakers, spouses, and other family members in the household. Nearly every participant's case had the occurrence of a packet of important information for the patient's spouse or caretaker. This information packet was referred to as an "emergency folder" in almost every case, also known by the more colorful title of "in case the world ends" folder by one patient and spouse. The purpose of this folder was to aggregate different kinds of printed documents, brochures, social security numbers, utility bills, passwords, and other types of health information the spouse or caretaker would need in case the patient dies or becomes incapacitated. These folders were spatially located in a common space both patients and caretakers were familiar with, often located closer to the caretaker or family members belongings in the home. This emergency folder exemplifies the role of space, availability, and accessibility of different information and different materialities to different social actors.

So far, findings have shown that personal health information management assemblages comprise a set of practices that concern the accessibility and availability of information. Now, I will show another set of practices uncovered by the analysis that concern practices of planning for the organization and use of health information. This includes the blue prints, plans, formulations, and other ways that patients learn to interact with health information. These practices then connect directly to the next section that reveals the practice of sense making in the constitution of this assemblage.

Participants' prior knowledge and experience with managing personal information, broadly speaking, was used as a template that was then directly applied to their use of health information. This prior knowledge was how all participants negotiated the planning and use of health information. Participants applied their understandings, strategies, and techniques from the ways they managed information in other parts of their lives, non-health information they manage in other contexts of life, to health information.

In the interviews, I learned that the participants have a variety of hobbies including cooking from recipes, sewing and working with patterns, writing music and looking up music notation, researching ice fishing, and researching golf. When talking about their personal health information management work and how these patients use a personal health record, it was impossible to separate out how they use information in other domains to inform how they work with health information. These personal hobbies all involve the collection, organization, management, and use of information. Participants learned from their hobbies how to bookmark online resources or develop organizational systems that supported their hobby and allowed them to increase skills. When participants articulated their strategies for health information management, they often started by discussing one of their hobbies as a blueprint or map for integrating their health information into their lives.

'But you know, when you're looking at your computer up here, they have the star, I learned if I hit that it keeps a list of what I want, so learned how to do that. I save 
recipes, I save because I sew a lot, I save patterns, I save sites that I wouldn't know in a million years to get back to that site. I wouldn't know how to do it, so I learned how to bookmark it' (Patient \#2251).

This patient was referring to the favorites menu on their Internet browser. Rather than printing out the information from the Internet as the patient previously had done, now the patient keeps those materials organized in a favorite bookmarks folder. This was learned to maintain their sewing hobby. The above quote was the preamble to further discussing how they keep health information for a specific disease they had been researching for several months. This new information organization management skill was learned in the context of a personal hobby of sewing, then applied to the organization and management of health information.

The above example shows a general script or plan that is then customized and applied to a specific context. This example is contrasted with another patient that, instead of storing web pages as links in the bookmarks bar, opted to save the web page as a PDF file and then store that file in a hierarchy of folders on their laptop hard drive. This organization and storage strategy were directly influenced by how they learned to store and organize documents in their business life. Many information management skills are learned and adapted from other areas of life, because no one teaches a course on how to be a patient. These prior information scripts and models are learned in other contexts of life and become integrated into a patient's personal health information management assemblage.

While the use of email to store digital documents was a clear practice many participants engaged with to increase the accessibility and availability of certain information, as previously shown, the use of email also became an organizing and planning practice in itself. This practice is explained by one participant thusly:

'And I'll email it to myself normally. And then move it to the folder and it stays there. I have email folders and those reference things and I have sixteen subfolders in my google mail and yeah. It doesn't matter if it's an e-receipt from Kmart or something from here [the VA] it gets moved to an email folder that I can go to and find the information quickly' (Patient \#8574).

Clearly, the patient learned this strategy from organization of other important digital documents. Rather than print them out or keep a file folder of many paper documents as others would, the patient used email as a filing system. This included sending PDF documents that originated in the PHR to the patient's own email address. In the multiple cases when email was an organizing strategy for filing electronic documents, the PHR functioned as a system that simply provided information to the patient. Even though the PHR had similar document organizing and management capabilities, this practice of staring documents in email was preferred.

The final set of practices that in part constitute the priming of the patient's personal assemblage are the ways in which sense making practices occur. These are the 
practices that patients employ to make decisions and use information in a way that meets their end goals. It is a similar notion to what Suchman refers to as plans and situated actions (Suchman 1985). While the patient has access to their own knowledge and lived experience, the patient also has the material tools, technologies, and documents where information is stored. These practices help patients make sense of information, answer questions they are asking, and also link to the second catalyst: actuating the assemblage through and with these practices. Sense making occurs through the various techniques, actions, or decisions that patients engage in with their personal health information. These actions are informed by the aforementioned planning and organizing practices. The practice of sense making is idiosyncratic and is cultivated through searching, organizing, and interacting with information. An example that occurred with every participant is the use of Google search. One participant narrated their own sense making process in the following way:

'I generally just google. I look for a variety of places some of the big names the Mayo Clinic the Cleveland Clinic those are, or WebMD, what you can get. What I do is I'm looking for patterns, I look for consistency. So, if I search through ten different websites for information on so and so and I'm getting the same basic thing in all of them I realize okay that's pretty much the standard. And if I find information that's all over the place I realize okay there's not a lot of consensus on it. So, I'm looking for consistency' (Patient \#2221).

What patient \#2221 is showing is how they navigate search and make sense of their results, and the kind of templates, scripts, or models they use to help make sense of the information. This particular patient was medically trained and educated, and that education clearly influences how they evaluate and make sense of health information. The sense making practice used here is expressed as identification of patterns or consistency across similar websites. This practice was developed by this participant and it is reliant on other practices of their health information management assemblage. Other participants have developed different practices for a similar web search. But because those other participants do not have a medical education, the same personal experience, or the same searching and information organization practices as participant \#2221 featured here, their sense making practices will differ. This is why personal health information management assemblages are personal and purposeful to patients. Patients are agentic actors engaged in an enterprise of personalizing, searching, organizing, managing, communicating, and working with health information mediated by social actors, technologies, and tools with a variety of materialities.

Other sense making practices include keeping notes and writing important questions on an index card that was always in a patients front shirt pocket, having a specific folder hierarchy and tags used in an email program to organize health documents, specific ordering and placement of medications in a cardboard box, using Google Docs to organize and share specific information with other people, 
using manila folders to organize prior military service health records that only exist in a paper format, internet search strategies, wall calendars to organize paper information, and dozens more practices are all sense making techniques that patients are their caretakers have developed.

A patient's current health condition and previous experiences with health overwhelmingly influence how a patient is able to make sense of information and engage with many other aforementioned practices. One participant expressed this concept directly and concisely when discussing a chronic condition she has been dealing with for over 5 years that, at the time, was undiagnosed. When asked about how she retains information and questions for a clinical appointment, she replied: "If I feel bad I try to remember, if I know that I've got an attention span of a gnat I bring a printout with me there and I ask the doctor" (Patient \#2251). The conversation that surrounded this quote was about the depletion of focus and health that occurred on an almost daily basis when the undiagnosed condition was at its worst. This permeated all aspects of his life and was especially insurmountable in attempts to research information online or sort through information on My HealtheVet when preparing for the next clinical appointment with a specialist. This conversation with Patient \#2251, as well as similar conversations with many others, indicates that the way we manage health information and can make sense of it is primarily influenced by our state of health in the moment and by prior experiences. If the patient does not have the mental capacity to engage with information, the help of other people or alternate systems is required. In the case of Patient \#2251 the convenience of paper and the ability to print information from the PHR was key to direct the conversation in clinical appointments because this patient used the paper as a conversational tool. They could hold it and point to it, write notes on it, or hand the paper to the provider and ask them to write notes (the name of a drug) down on the paper, as she often did. When asked further about this practice she conveyed that paper did not run out of batteries like a phone would, and that paper did not feel rude in the clinical appointment like using a phone or a tablet did.

As patients engage with information practices and planning practices these in turn influence and in part constitute their sense making practices. These concepts are reciprocal: as people learn to "deal" with information in different aspects of their lives, they apply those learned scripts or models to other information management topics or domains. These three practices of information practices, planning practices, and sense making practices, all that constitute the first theme of assemblages that concern the priming or map making of the assemblage. The second theme, the other half of the important conceptual components, are the other actors and materialities that come into play during the priming of the assemblage. In the next section, I focus on these two components: how social actors constitute a personal health information assemblage, and how the materiality of information and tools matters to personal assemblages. 


\subsection{Actuating the assemblage}

Personal networks are leveraged by every patient as part of the constitution of their personal health information management assemblages. These personal networks include family members, spouses, and close family friends. People closest to the patient's life, and those that live with the patient, assume a vital role in stabilizing the assemblage. This stabilization occurs through caretakers adopting, assisting, and supporting the patients established information practices and practices for planning and sense making. The role of personal networks in health information management is exemplified in one participant's management of anxiety in public and before clinical appointments. The caretaker played a pivotal role in helping the patient remember questions, focus the patient's thoughts, and supported the patient in the waiting room through conversation and relaxation techniques.

'So I have a traumatic brain injury (TBI) and I forget a lot of things, so she goes and she takes care of, well she takes care of a lot of things. And my post-traumatic stress disorder (PTSD) I have a lot of depression so there's a lot of times where I'm like fuck it I'm not doing anything but she takes up a lot of it. She goes to my appointments to say look, you know, because I'll get there, I'll forget, and I'll forget to look at my phone. So she'll go and she'll be like look you need to look at your phone and she'll sit there and if I'll look at a question on my phone or bullet point and I'll be like I don't know what the fuck this means, she'll pick it up and she'll be like you know, here's a hint...we'll sit down like the day before and she'll be like look, you know, what were you going to ask him, "oh fuck I don't know". She'll like throw me hints and if I don't get it she'll be like alright dumb ass this is what you had to ask' (Patient \#6763).

This brazen quote is one of the best direct representations of the information management roles that caretakers and family members play. This portion of the interview transcript shows that, due to the patient's current health status (TBI and PTSD), the patient often relies on another person that is both familiar with that health status and ways in which the patient manages information. The caretaker provided supportive clues and hints before and during clinical appointments. The caretaker also knew that questions and ideas were written down on the patient's phone to create a continuous log of questions. Shared access is an inherent trait of assemblages, and that trait is showcased in this characteristic of how personal social networks become connected to the patient's assemblage. Caretakers are exposed to and understood the patient's information practices, planning practices, and sense making practices. Caretakers were able to support the patient's personal practices through knowing how they capture information, the kind of information they manage and organize, and the kinds of practices that patients engage with in order to make sense of that information to support their care. 
Of particular interest to show how these assemblages are personal, and what matters help personalize the assemblage, is the nature of the patient's health concerns. Acute symptoms or mental and behavioral health arrangements are essential traits that contribute to the shaping of the patient's health information management assemblage. Routine checkups or other minor clinical appointments contained almost no shared information practices. This is not to say that caretakers were not supportive of the patient, but the role of the other person was not the same as the roles taken by social actors in mental and behavioral health contexts. This difference in when and how a caretaker helped with information management tasks is key to understanding the health information needs of patients. Certain conditions require a caretaker to be enrolled as an information storage and retrieval agent that adapts to shifting contexts.

These findings echo previous work that frame the patient caretaker relationship as a collaboration (e.g. Nunes and Fitzpatrick 2015) where caretakers help when the patient is in a difficult or compromised physical and emotional state. Additionally, that many tools designed for patients do not include the caretaker in their design or functionality. This is certainly accurate of My HealtheVet (MHV), which only allows for the patient to be logged in as their own identity, having previously been authenticated in person at a VA field office. However, in every single case where the caretaker would at some point log into MHV for the patient to access health information. This is not a supported function of the health record as, at the time of this research, account delegation was not supported in the health record.

The final component that emerged from this analysis is the role of materiality in the patient's personal health information management assemblage. All of the previously discussed practices for information management, planning, and sense making are practices that are communicated through and mediated by the different materialities in the patient's assemblage. Physical qualities of the objects and information these patients use include tools like laptops, tablets, and phones or objects like paper, printed calendars, scraps of information, brochures, and notebooks. The digital qualities are of electronic documents on tablets, phones and laptops (Leonardi 2010). The materiality of information management is a key characteristic of assemblages. Materiality plays into how arrangements are configured and what information management decisions are made. Through interviews and observations of how these participants use digital devices and what printed information they carry on hand, it was evident that purposeful decisions are made for why a particular technology or type of material is used, and those decisions impact the patient's possibilities of their practices. The material of information matters (Barad 2003). Despite the ability to "go paperless" with tablets and smart phones, the use of paper is still important and fills a unique role.

Establishing an appointment in a calendar can be done in a variety of ways. For various reasons, participants prefer either a paper calendar or a digital calendar, while some prefer to use both. Each of these devices enable other actions and options for the patient. In the case of digital calendars, notifications could be automatically 
triggered before appointments and sent to devices. Whereas physical calendars were part of a routine or ritual. The participant was usually in a specific place every day and would review their daily events at the location of the paper calendar. Each material option for a calendar comes with different challenges. The struggle to use both is exemplified by one participant:

'This is like my constant battle [organizing both personal and health information], my whole life is to figure out some way of staying organized here. I oscillate back and forth between paper and electronics, and everything. I went from full size calendars to little calendars to doing it on the computer, to keeping it on Outlook to this care manager thing that we have at work now to using it on my phone. I find myself trying to stay organized in so many different ways that I'm disorganized, you know what I'm saying. I'm trying to find my way of staying organized, you know. Am I a laptop guy? I'm very envious of people, you know, and I ask people at work, too. I'm like you use that; I see you keep your calendar. Because I'm very interested in how people stay organized. Cause I'm very interested in this at work, you know, cause mentally ill are always missing their appointments and I'm like you've got to keep a calendar' (Patient \#1079).

This quote typifies the material characteristics found in these health information arrangements: the role of physical and digital materials, the predefined (or not) information organization plans the participant has, stabilization of these components, and the stress of disorganization. This quote identifies the binary between trying to keep health information entirely digital or entirely paper based.

Materiality also manifests through discourse about the concept of security. Specifically, there is a perception that physical information is secure and can be securely discarded. Alternatively, the notion of ephemerality is associated with digital information. The idea is that a person does not really own something unless it is held in that person's own hands. It is also challenging to reference information if the documents are digital. If a document is printed it becomes permanent, tangible, and accessible. If information is digital, however, it is often seen as easily lost, nonpermanent, insecure, and ephemeral. Printed information was overwhelmingly referred to as a "hard copy" and preferred for certain types of documents because of the ability to store printed documents in a physical location that provided the patient with a greater sense of security than if that were a digital document. This was especially relevant concerning sensitive health information. It is important to patients who use paper documents to personally and reliably destroy those documents. When paper is the main choice of information storage, those patients also had paper shredders and specialized techniques for destroying information they no longer needed. One of the more elaborate and vivid examples for paper document disposal follows:

'It's [paper shredder] almost like packing material, mine makes like little oblong things, it's a cross cut and it makes little diamonds. It's impossible [to reconstruct], 
you go like this [throws hands in the air] and there's dust everywhere so it's really small. But yeah it's good for [burning]. What I've done before I moved, like, I called them paper balls. You get them [paper shredder remains] soaking we and then I had this little press thing that a buddy of mine made that you compact it and then it dries out with the weight of it and then you have this like fire log ball thing for the bottom [of a fire pit] to light it' (Patient \#1630).

Destroying paper is unlike the deletion of digital objects: there is something physical to be destroyed. With digital documents, participants perceived that deleted information could be easily retrieved or copied and that these documents were never truly secure. These participants kept paper records and would shy away from keeping that information digital. The perception of security influenced the type of websites patients would access or what kind of information they would look for when using the internet. In multiple instances, email was avoided on mobile phones because it was perceived to be insecure.

Another practice of material arrangements is the familiarity the respondent has with the material decisions they have made. Specifically, familiarity with the technology is an important factor in determining the practices they are likely to employ. Interviewees compensate for lacking advanced computer use and Internet research practices with other ways such as writing down questions and search results on paper and printing out webpages. Participants with more familiarity in using the Internet to research health did things like use bookmarks, cut and paste text, and save PDF documents in an organized location. These participants enacted digital skills-based practices. However, patients may be familiar with performing work using physical tools and documents and that will influence the information management decisions they make. The story from the respondent below shows the materiality characteristics of health information assemblages.

'Yeah but you know what, it's kind of funny too in the same way cause I tell my wife about this with a range card, like for a weapon, I don't know if you're familiar with it or not. But we have range cards for like machine guns and other weapons. When I first went in the Army we used to write it on like a piece of paper. Then we got like laminated ones and then we got pens and alcohol markers and then we got Plexiglas and different markers. We have all this stuff and brought all this different stuff, and you know, by the time my career is over you know what I figured out the best thing to do is? An MRE box and pen or pencil, what's the best way to do this. The best way to do this range card after experiencing all this stuff for me for all these years, was to teach people how to write, to draw the range card and then they could just write it on anything instead of having to worry about bringing all these freakin' special pens and all of these freakin' Plexiglas crap, and all this other crap to the field all the time. It's like I went full circle. It's like I started out with a pencil and paper and tried all this electronic, well not the electronic stuff, but basically the electronic stuff too because the batteries became a problem and if the stuff breaks 
you're screwed, you don't have it written down anywhere, you can read it anymore. So it's like oh man this is cool but it's not really practical, it's better just to write it down. So it kind of went like full circle with that and that was kind of an eye-opening experience for me because it was years later. Oh we got to get better, we got to get better, no we don't. There was nothing wrong with it, just leave it alone' (Patient \#1079).

The core element of this story is the changing materiality and decisions of other tools such as pens, papers, and writing surfaces, which later became electronic. Ultimately, for this participant the materiality of the specific writing surface, the meals ready to eat (MRE) box, and a pen or pencil was the preferred way to construct the range card. Certainly, there were other options for constructing the range card, even using a digital tool. For multiple reasons the materiality mattered to the task the respondent was trying to accomplish. These decisions are no different in the arrangements of patients managing health information. Material choices are made based on other characteristics previously discussed in the findings section. Some of these choices are made based on familiarity or other preferences, but the key idea is that PHIM assemblages maintain a characteristic of material choice.

\section{Discussion and conclusion}

With the drastic growth in personal health tracking, online health support communities, and the myriad of ways patients can access information and how patients are tracked through their life and through the healthcare system, it is more critical than ever to understand personal health information management (PHIM) in a way that keeps pace with other technological and information management phenomena. Currently, the main conceptualization of PHIM is as a process of patients capturing information, organizing it, and integrating it into their lives so that it becomes useful to them (Civan et al. 2006; Pratt et al. 2006). I contend that PHIM is far more complex and important than a simple information management process. It is important for academics to address prior calls to action that move towards a more sociotechnical treatment of the patient's health information work (Purin and Piras 2011). As personal health records (PHRs), home genetic tests, social media networks, and smart phone sensors all advance in their sophistication, we cannot be stuck in the same way of thinking about personal information management when it comes to health. To advance current thinking on PHIM and the use of PHRs I pursue PHIM as a practice-oriented assemblage, this position highlights the materials, practices, and people that propel patients toward their goals.

Findings from the analysis using this approach bring to light three important concepts that must be held constant in this holistic view. I will now describe each of these concepts that a researcher commits to when they take up this approach. I will then discuss some insights from these concepts and this study for the future of PHIM and PHR research. First, PHIM is personal and that patients are agentic throughout 
the decisions and practices I have previously described. This means patients are actively creating or constructing this assemblage, it is a purposeful act. This is reflected in the findings and shown in Table 2. From the initial catalyst of doing, planning, sense making, and creating these assemblages through information practices; then to the next catalyst of maintaining and stabilizing the assemblage with personal networks and material.

The personal nature I discuss throughout the findings add another perspective onto the notion of "personal" in personal health records. Previous work has shown that the personal connotes both a type of personal responsibility or interpretation of the information, as well as personal in terms of privacy (Piras and Zanutto 2014). I would expand this notion to include personal in terms of lived experience of the patient's body and lived experience with the management of other types of information, as was shown with patient hobbies. Personal health conditions, such as mental health and PTSD, strongly influence the practice of health information management. Although the influence of patient's disease and illness on work is not entirely new (Berg and Bowker 1997), these findings do present a new perspective for PHIM research showing the extent of the connection between information management and experience of illness. If assemblages are about producing possibilities and driving them forward, the patient's vitality has relevance in those possibilities. Particularly in the first catalyst of priming PHIM where patients are making the most decisions throughout their information practices, planning, and sense making work.

The second commitment derived from this work is that PHIM is mediated through physical or digital materials that influence information practices. Information does not simply wash over the patient, but it is actively used, shared, and made actionable through the use of different physical or digital tools. The selection and use of those tools, be they physical or digital, is always an intentional and often well thought out choice. I use the term material in this second commitment to refer to the actual physical characteristics of the tool doing the mediation. Such as physical documents and physical organizational systems or digital systems and files stored on hard drives. Although hard drives and laptops are as physical as printed paper documents and file folders, I refer to the information they mediate. Many of the interviews contained discussions on patients negotiating with themselves if they wanted to keep health information in a digital format or a physical format. Those patients were thinking about the material that would mediate their information. The patients understood that deciding on the material will mediate their information means their future practices will be shaped or shifted. This is shown perfectly in the previous quote from patient \#1079 about creating the range finder card. A tool used to judge the distance of different objects. They spend significant amounts of time learning and thinking about all the different ways they can create a better version of this tool. The only differences between them they describe are material differences, using different paper and cardboard and plexiglass to a digital version. For them, the best version is one they make with essentially leftover materials. The choices they make are that of physical material and a Gibson notion of affordance (Gibson 1986). 
Much of the patient experience when communicating with the healthcare system is mediated through technology such as the ability to message providers through a computer-mediated-communication system (Byrne et al. 2009) and the ubiquity of information technology to mediate aspects of healthcare will only increase over time (Chen et al. 2013). I would posit that the institutional reinforcement of computermediated communication with patients will impact their personal decisions for selecting supportive tools and systems. The physical or digital materiality of tools to support PHIM is important because it impacts the practices of information management. Participants that were "all digital" in their information practices (Leonardi 2010) meant that the patient has a greater volume of data to manage with a wider variety of data. Whereas physical material, paper documents, were usually seen as secure and private that allowed for practices of control and security in the personal sense as previously discussed. The mediation of information through different materials leads to different practices and possibilities. Two of the previously established features of assemblages are the desire of heterogeneous actors to evoke the goals of the assemblage and for assemblages to produce possibilities. The materials of the assemblage will alter the goals and possibilities of PHIM based on patients that choose to use paper documents to manage their information or collections of digital documents.

The third commitment is the materiality of information practices. In the second commitment I use the term materiality in what Leonardi (2010) calls the first definition of material: "Senses related to physical substance", meaning the actual physicality of the object of study. For the purposes of this study that refers to if the information is mediated through digital means or through physical means such as white boards and paper documents. With this third commitment I use the term in a similar way to Orlikowski's technologies-in-practice concept. That is to say the material is not what matters, what matters is what the person does with the material, and though this practice is what constitutes the materiality of the object (Orlikowski 2000). I find this concept logically connects with the interpretation of personal health information management assemblages I have provided because this notion of materiality further supports the personal nature and the practice-oriented framework. Furthermore, when attending to PHIM as an assemblage the researcher is committed to understanding the practices of the patient's assemblage. Within those practices the patients are creating materials that motivate and produce possibility such as selfmanagement, collaboration with care takers, secure messaging with providers, or finding answers and making sense of a difficult diagnosis. Every participant had access to the same My HealtheVet personal health record, but most all of them had different personal practices of how they used the PHR. This is the materiality of the PHR, and other PHIM tools, in practice. To some those practices equated the PHR to a reference tool, to others an educational utility, and to others a document repository.

Furthermore, the materiality of information practice explains the differences observed between a PTSD patient compared to a patient attending an outpatient surgery. The material nature of a PTSD patient is having mental health resources 
at the ready. The parts of the PHR they interact with are the clinical notes from their psychologist, secure messaging, and prescription renewals are very important. Through their information practices and relational arrangements, we see how the material of the PHR is shaped. Whereas the PHR materiality for the patient going in for an outpatient surgery looks very different. They book an appointment online and maybe reference some older information in the PHR to be ready for an appointment. Their practices are primarily offline, reviewing a brochure provided by the clinician and writing questions about the procedure down on a notecard. Each of these patients have the same level of access to the PHR, yet the material functions of their use are different. This fits into the patients PHIM assemblage because we have a more personalized understanding of what the PHR is and how those materials motivate the assemblage.

The research presented in this paper aims to advance the growing literature in personal health information management and personal health records. The findings also contribute to patient-oriented and patient-centered services, including work in the medical home and patient work at home (Aarhus and Ballegaard 2010; Moen and Brennan 2005; Piras and Zanutto 2010), mobile health information management (Klasnja et al. 2010b; Klasnja and Pratt 2012), medication management (Mickelson et al. 2015; Palen and Ballegaard 2006), environments and settings of health information work (Klasnja et al. 2010a; Unruh and Pratt 2008; Unruh et al. 2010), and PHRs as technical actors for how patients interact with the healthcare system and manage information (Østerlund et al. 2005; Purin and Piras 2011). Because all of these contexts involve aspects of personal health information management and the patients personal situated practices including materialities, social actors, technologies, tools, and shifting contexts.

Open Access This article is distributed under the terms of the Creative Commons Attribution 4.0 International License (http://creativecommons.org/licenses/by/4.0/), which permits unrestricted use, distribution, and reproduction in any medium, provided you give appropriate credit to the original author(s) and the source, provide a link to the Creative Commons license, and indicate if changes were made.

\section{References}

Aarhus, Rikke; and Stinne Aalokke Ballegaard (2010). Negotiating Boundaries: Managing Disease at Home. In: CHI 2010. Proceedings of the SIGCHI conference on Human Factors in Computing Systems, Atlanta, GA, USA, 10 - 15 April 2010. New York: ACM Press, pp. 1223-1232.

Agarwal, Ritu (2009). Personal Health Information Management and the Design of Consumer Health Information Technology. College Park, Maryland: Agency for Healthcare Research and Quality, U.S. Department of Health and Human Services.

Archer, Norm; Urslin Fevrier-Thomas; Cynthia Lokker; Ann McKibbon; and Sharon Straus (2011). Personal health records: a scoping review. Journal of the American Medical Informatics Association, vol. 18, no. 4, pp. 515-522. https://doi.org/10.1136/amiajnl-2011-000105 
Ball, Marion; Melinda Costin; and Christoph Lehmann (2008). The personal health record: consumers banking on their health. Studies in Health Technology and Informatics, vol. 134, pp. 35-46.

Barad, Karen (2003). Posthumanist Performativity: Toward an Understanding of How Matter Comes to Matter. Signs: Journal of Women in Culture and Society, vol. 28, no. 3, pp. 801-831. https:// doi.org/10.1086/345321

Bennett, J (2010). Vibrant Matter: a political ecology of things, London: Duke University Press

Berg, Marc (1999). Patient care information systems and health care work: A sociotechnical approach. International Journal of Medical Informatics, vol. 55, no. 2, pp. 87-101.

Berg, Marc; and Geoffrey Bowker (1997). The Multiple Bodies of the Medical Record: Toward a Sociology of an Artifact. The Sociological Quarterly, vol. 38, no. 3, pp. 513-537.

Berg, Marc; Chris Langenberg; Ignas vd Berg; and Jan Kwakkernaat (1998). Considerations for sociotechnical design: experiences with an electronic patient record in a clinical context. International Journal of Medical Informatics, vol. 52, no. 1-3, pp. 243-251.

Brennan, Patricia Flatley; Stephen Downs; Gail Casper; and Daniel Kenron (2007). Project HealthDesign: stimulating the next generation of personal health records. In: AMIA 2007. Proceedings of the American Medical Informatics Association Annual Symposium, Chicago, Illinois, 10 - 14 November 2007, pp. 70-4. https://www.ncbi.nlm.nih.gov/pmc/articles/PMC2655909/

Byrne, John; Shane Elliott; and Anthony Firek (2009). Initial experience with patient-clinician secure messaging at a VA medical center. Journal of the American Medical Informatics Association, vol. 16, no. 2, pp. 267-270. https://doi.org/10.1197/jamia.M2835

Chen, Yunan; Karen Cheng; Charlotte Tang; Katie Siek; and Jakob Bardram (2013). Is my doctor listening to me?: impact of health it systems on patient-provider interaction. In: CHI 2013. Proceedings of the SIGCHI conference on Human Factors in Computing Systems, Paris, France, 27 April - 2 May 2013. New York: ACM Press, pp. 2419-2426. https://doi.org/10.1145/ 2468356.2468791

Civan, Andrea; Meredith Skeels; Anna Stolyar; and Wanda Pratt (2006). Personal health information management: consumers' perspectives. In AMIA 2006. Proceedings of the American Medical Informatics Association Annual Symposium, San Francisco, Calif., USA, 14 - 18 November 2006. pp. 156-60. https://www.ncbi.nlm.nih.gov/pmc/articles/PMC1839450/

Civan, Andrea; David McDonald; Kenton Unruh; and Wanda Pratt (2009). Locating Patient Expertise in Everyday Life. In GROUP 2009. Proceedings of the 2009 international ACM conference on supporting group work, ACM, Sanibel Island, Florida, 10 - 13 May 2009. New York: ACM Press, pp. 291-300.

Cox, Andrew (2012). An exploration of the practice approach and its place in information science. Journal of Information Science, vol. 38, no. 2, pp. 25-28. https://doi.org/10.1177/ 0165551511435881

Davidson, Elizabeth; Carsten S. Østerlund; and Mary Grace Flaherty (2015). Drift and shift in the organizing vision career for personal health records: An investigation of innovation discourse dynamics. Information and Organization, vol. 25, no. 4, pp. 191-221. https://oi.org/10.1016/ j.infoandorg.2015.08.001

DeLanda, Manuel (2006). A New Philosophy of Society: Assemblage Theory and Social Complexity. Bloomsbury Academic.

Deleuze, Gilles; and Félix Guattari (1987). A Thousand Plateaus. (B. Massumi, Ed.). Minneapolis: University of Minnesota Press.

Gherardi, Silvia (2012). How to Conduct a Practice-Based Study: Problems and Methods (1st ed.). Cheltenham, UK: Edward Elgar Pub.

Gibson, James; (1986). The ecological approach to visual perception. Hillsdale, N.J.: Lawrence Earlbaum.

Greenhalgh, Trisha; and Deborah Swinglehurst (2011). Studying technology use as social practice: the untapped potential of ethnography. BMC Medicine, vol. 9, no. 1, pp. 45. https://oi.org/10.1186/ 1741-7015-9-45 
Henningsson, Stefan; and Ole Hanseth (2011). The essential dynamics of information infrastructures. In: ICIS 2011. Thirty Second International Conference on Information Systems, Shanghai, China, 4 - 7 December 2011. pp. 1-19.

Hersh, William (2002). Medical Informatics: Improving Health Care Through Information. The Journal of the American Medical Association (JAMA), vol. 288, no. 16, pp. 1955-1958. https:// doi.org/10.1001/jama.288.16.1955

Hill, Jason; Sandra Burge; Anna Haring; and Richard a Young (2012). Communication Technology Access, Use, and Preferences among Primary Care Patients: From the Residency Research Network of Texas (RRNeT). Journal of the American Board of Family Medicine (JABFM), vol. 25, no. 5, pp. 625-634. https://doi.org/10.3122/jabfm.2012.05.120043

Jarrahi, Mohammad Hossein (2015). Digital and physical materiality of information technologies: The case of fitbit activity tracking devices. In: HICSS 2015. Proceedings of the Annual Hawaii International Conference on System Sciences, Kauai, Hawaii, USA, 5 - 8 January 2015. Washington, DC: IEEE Computer Society, pp. 1768-1777. https://doi.org/10.1109/ HICSS.2015.214

Jones, William (2008). Keeping Found Things Found: The Study and Practice of Personal Information Management (1st ed.). Burlington, MA: Elsevier Inc.

Kim, Kyungsook; and Eun-shim Nahm (2012). Benefits of and barriers to the use of personal health records (PHR) for health management among adults. Online Journal of Nursing Informatics, vol. 16, no. 3.

Kim, Eung-Hun; Anna Stolyar; William B Lober; Anne L Herbaugh; Sally E Shinstrom; Brenda K Zierler; ... Yongmin Kim (2009). Challenges to using an electronic personal health record by a low-income elderly population. Journal of Medical Internet Research, vol. 11, no. 4, pp. e44. https://doi.org/10.2196/jmir.1256

Klasnja, Predrag; and Wanda Pratt (2012). Healthcare in the pocket: mapping the space of mobilephone health interventions. Journal of Biomedical Informatics, vol. 45, no. 1, pp. 184-198. https:// doi.org/10.1016/j.jbi.2011.08.017

Klasnja, Predrag; Andrea Civan Hartzler; Kent T Unruh; and Wanda Pratt (2010a). Blowing in the Wind: Unanchored Patient Information Work during Cancer Care. In: CHI 2010. Proceedings of the SIG CHI conference on Human factors in computing systems, Atlanta, Georgia, 10 - 15 April 2010. New York: ACM Press, pp. 193-202. https://doi.org/10.1145/1753326.1753355

Klasnja, Predrag; Andrea Hartzler; Christopher Powell; Giovandy Phan; and Wanda Pratt (2010b). Health Weaver Mobile: Designing a Mobile Tool for Managing Personal Health Information during Cancer Care. In: AMIA 2010. Proceedings of the American Medical Informatics Association Annual Symposium, Washington, DC, 13 - 17 November 2010. pp. 392-6. https:// www.ncbi.nlm.nih.gov/pmc/articles/PMC3041373/

Kutz, Daniel; and Hamid Ekbia (2011). Designing for the Invincible: Health Engagement and Information Management. In: HICSS 2011. Proceedings of the Annual Hawaii International Conference on System Sciences, Kauai, Hawaii, USA, 3 - 7 January 2011. Washington, DC: IEEE Computer Society, pp. 1-10. https://doi.org/10.1109/HICSS.2011.150

Kuutti, Kari; and Liam J. Bannon (2014). The turn to practice in HCI: Towards a research agenda. In M. Jones, et al. (eds.), CHI'14: Proceedings of the 32nd Annual ACM Conference on Human Factors In Computing Systems, Toronto, Canada, 26 April - 1 May 2014. New York: ACM Press, pp. 3543-3552.

Lahtiranta, Jamnne (2009). Current challenges of personal health information management. Journal of Systems and Information Technology. vol. 11. no. 3, pp. 203-43.

Leonardi, Paul (2010). Digital materiality? How artifacts without matter, matter. First Monday, vol. 15, no. 6. https://doi.org/10.5210/fm.v15i6.3036e

Lindeman, David (2010). Lessons from a Leader in Telehealth Diffusion: A Conversation with Adam Darkins of the Veterans Health Administration. Ageing International. https://oi.org/10.1007/ s12126-010-9079-7 
Mickelson, Robin; Matt Willis; and Richard Holden (2015). Medication-related cognitive artifacts used by older adults with heart failure. Health Policy and Technology, vol. 4, no. 4, pp. 387-398. https://doi.org/10.1016/j.hlpt.2015.08.009

Miles, Matthew; and Michael Huberman (1994). Qualitative data analysis: an expanded sourcebook (1st ed.). Thousand Oaks, California: Sage.

Moen, Anne; and Patricia Flatley Brennan (2005). Health @ Home: The Work of Health Information Management in the Household (HIMH): Implications for Consumer Health Informatics (CHI) Innovations. Journal of the American Medical Informatics Association, vol. 12, no. 6, pp. 648 .

Muller, Martin (2015). Assemblages and actor-networks: Rethinking socio-material power, politics and space. Geography Compass, vol. 9, no. 1, pp. 27-41. https://doi.org/10.1111/gec3.12192

Nazi, Kim M (2013) The Personal Health Record Paradox: Health Care Professionals' Perspectives and the Information Ecology of Personal Health Record Systems in Organizational and Clinical Settings. Journal of Medical Internet Research, vol. 15, no. 4, pp. e70. https://doi.org/10.2196/ jmir.2443

Nazi, Kim M.; Timothy P. Hogan; Todd H. Wagner; D. Keith McInnes; Bridget M. Smith; David Haggstrom; ... Frances M. Weaver (2010). Embracing a health services research perspective on personal health records: lessons learned from the VA My HealtheVet system. Journal of General Internal Medicine, vol. 25, no.1, pp. 62-67. https://doi.org/10.1007/s11606-009-1114-6

Northcutt, Norvell; and Danny McCoy (2004). Interactive qualitative analysis: a systems method for qualitative research (1st ed.). Thousand Oaks, California: Sage.

Nunes, Francisco; and Geraldine Fitzpatrick (2015). Self-Care Technologies and Collaboration. International Journal of Human-Computer Interaction, vol. 31, no. 12, pp. 869-881. https:// doi.org/10.1080/10447318.2015.1067498

Orlikowski, Wanda J. (2000). Using Technology and Constituting Structures: A Practice Lens for Studying Technology in Organizations. Organization Science, vol. 11, no. 4, pp. 404-428. https:// doi.org/10.1287/orsc.11.4.404.14600

Orlikowski, Wanda J.; and Susan V. Scott (2008). Sociomateriality: Challenging the separation of technology, work and organization. The Academy of Management Annals, vol. 2, no. 1, pp. 433474. https://doi.org/10.1080/19416520802211644

Østerlund, Carsten; Nienke P Dosa; and Catherine Arnott Smith (2005). Mother Knows Best: Medical Record Management for Patients with Spina Bifida During the Transition from Pediatric to Adult Care. In AMIA 2005. Proceedings of the American Medical Informatics Association Annual Symposium, Washington, DC, USA, 22 - 26 October 2006, pp. 580-584. https:// www.ncbi.nlm.nih.gov/pmc/articles/PMC1560796/

Østerlund, Carsten; Finn Kensing; and Elizabeth Davidson (2011). Personal Health Records in the US and Denmark: From visions to versions? In Bjørn et al. (eds), Infrastructures for Healthcare: Global Healthcare: Proceedings of the 3rd International Workshop 2011, IT University of Copenhagen, pp. 13-16.

Østerlund, Carsten; Finn Kensing; and Silvia Gherardi (2014). Personal Health Records: Empowering patients through information systems? Information Technology \& People, vol. 27, no. 4, pp. 390-396.

Palen, Leysia; and Stinne Aaløkke Ballegaard (2006). Of Pill Boxes and Piano Benches: "Homemade" Methods for Managing Medication. In CSCW 2006. Proceedings of the ACM Conference on Computer Supported Cooperative Work, Banff, Alberta, Canada, 4-8 November 2006. New York: ACM Press, pp. 79-88.

Piras, Enrico Maria (2016). The Changing Locus of Health Data Production and Use: PatientGenerated Health Data, Observations of Daily Living, and Personal Health Information Management. In COOP 2016. Proceedings of the international conference on the Design of Collaborative Systems, Trento, Italy, 22 - 27 May 2016, pp. 1-7. 
Piras, Enrico Maria; and Alberto Zanutto (2010). Prescriptions, X-rays and Grocery Lists. Designing a Personal Health Record to Support (The Invisible Work Of) Health Information Management in the Household. Computer Supported Cooperative Work (CSCW), vol. 19, no. 6, pp. 585-613. https:// doi.org/10.1007/s10606-010-9128-5

Piras, Enrico Maria; and Alberto Zanutto (2014). "One day it will be you who tells us doctors what to do!". Exploring the "Personal" of PHR in paediatric diabetes management. Information Technology and People, vol. 27, no. 4, pp. 421-439. https://doi.org/10.1108/ITP-02-2013-0030

Pratt, Wanda; Madhu C. Reddy; David W. McDonald; Peter Tarczy-Hornoch; and John H. Gennari (2004). Incorporating ideas from computer-supported cooperative work. Journal of Biomedical Informatics, vol. 37, no. 2, pp. 128-137. https://doi.org/10.1016/j.jbi.2004.04.001

Pratt, Wanda; Kenton Unruh; Andrea Civan; and Meredith Skeels (2006). Personal health information management. Communications of the ACM, vol. 49, no. 1, pp. 51-55.

Purin, Barbara; and Enrico Maria Piras (2011). Personal Health Records among Institutions, Medical Records, and Patient Wisdom: A Socio-technical Approach. In M. Kostkova and P. Szomszor (eds), Electronic Healthcare. Springer-Verlag., pp. 151-158. https://doi.org/10.1007/978-3-64223635-8

Roehrs, Alex; Cristiano André da Costa; Rodrigo da Rosa Righi; and Kleinner Silva Farias de Oliveira (2017). Personal Health Records: A Systematic Literature Review. Journal of Medical Internet Research, vol. 19, no. 1, pp. e13. https://doi.org/10.2196/jmir.5876

Saldana, Johnny (2013). The coding manual for qualitative researchers (2nd ed.). Los Angeles: Sage. Sassen, Saskia (2005). Territory, Authority, Rights. Princeton, NJ: Princeton University Press.

Sawyer, Steve; Kevin Crowston; and Rolf T. Wigand (2014). Digital assemblages: evidence and theorising from the computerisation of the US residential real estate industry. New Technology, Work and Employment, vol. 29, no. 1, pp. 40-56. https://doi.org/10.1111/ntwe.12020

Smith, Aaron (2012). Nearly half of American adults are smartphone owners. Washington, D.C. Retrieved from Pew Research Center's Internet \& American Life Project

Suchman, Lucy (1985). Plans and situated actions: The problem of human-machine communication. New York, NY, US: Cambridge University Press

Swan, Melanie (2009). Emerging patient-driven health care models: an examination of health social networks, consumer personalized medicine and quantified self-tracking. International Journal of Environmental Research and Public Health, vol. 6, no. 2, pp. 492-525. https://doi.org/10.3390/ ijerph6020492

Taha, Jessica; Sara J Czaja; Joseph Sharit; and Daniel G Morrow (2013). Factors affecting usage of a personal health record (PHR) to manage health. Psychology and Aging. American Psychological Association. Retrieved from https://www.ncbi.nlm.nih.gov/pubmed/24364414

Unruh, Kenton T; and Wanda Pratt (2007). Patients as actors: the patient's role in detecting, preventing, and recovering from medical errors. International Journal of Medical Informatics, vol. 76 Suppl 1, pp. S236-S244. https://doi.org/10.1016/j.jimedinf.2006.05.021

Unruh, Kenton T; and Wanda Pratt (2008). Barriers to Organizing Information during Cancer Care: "I don't know how people do it". In: AMIA 2008. Proceedings of the American Medical Informatics Association Annual Symposium, Washington, DC, USA, 8 - 12 November 2008. pp. 742-746.

Unruh, Kenton T; Meredith Skeels; Andrea Civan-Hartzler; and Wanda Pratt (2010). Transforming Clinic Environments into Information Workspaces for Patients. In: CHI 2010. Proceedings of the SIG CHI conference on Human factors in computing systems, Atlanta, Georgia, 10 - 15 April 2010. New York: ACM Press, pp. 183-192. https://doi.org/10.1145/1753326.1753354

Ventres, William; Sarah Kooienga; Nancy Vuckovic; Ryan Marlin; Peggy Nygren; and Valerie Stewart (2006). Physicians, patients, and the electronic health record: An ethnographic analysis. Annals Of Family Medicine, vol. 4, no. 2, pp. 124-131. https://doi.org/10.1370/afm.425

Walsham, Geoff (2006). Doing Interpretive Research. European Journal of Information Systems, vol. 15 , no. 3 , pp. $320-330$. 
Wulf, Volker; Claudia Müller; Volkmar Pipek; David Randall; Markus Rohde; and Gunnar Stevens (2015). Practice-based computing: Empirically grounded conceptualizations derived from design case studies. In V. Wulf; K. Schmidt; and D. Randall (eds.), Designing Socially Embedded Technologies in the Real-World, London: Springer, pp. 111-150.

Yin, Robert (2014). Case Study Research: Design and Methods (5th ed.). Thousand Oaks, California: Sage Publications.

Publisher's Note Springer Nature remains neutral with regard to jurisdictional claims in published maps and institutional affiliations. 